\title{
SHAKESPEARE Y HOBBES ${ }^{*}$
}

\section{Margarita Costa UBA-UNLP}

No cabe duda de que tanto para un dramaturgo como para un político, el lenguaje es una herramienta fundamental de la que tanto el uno como el otro se valen para elaborar y comunicar sus ideas a un auditorio público, ya se trate de los espectadores de una obra teatral como de un conjunto de ciudadanos o súbditos en su condición de tales. La diversidad de circunstancias y contextos, así como los distintos fines perseguidos en uno y otro caso, pueden llevarnos a pensar que la posición de cada uno de ellos acerca del uso que puede o debe hacerse de este poderoso instrumento ha de diferir diametralmente. Si el dramaturgo quiere entretener o conmover a su auditorio y el político conducirlo o persuadirlo, las palabras tendrán un valor relativo a esas finalidades y nadie se confundirá acerca de la modalidad del discurso y su recepción respectiva.

No obstante, puede advertirse en ciertos casos una finalidad coincidente entre ambos: transmitir un mensaje, mostrando una realidad, u ocultándola. Si la atmósfera social e histórica es compartida por el dramaturgo y el político, no sería extraño que el mensaje tendiente a la mostración u ocultamiento de la realidad fuese semejante. La diferencia de género no llegaría al punto de hacer imposible o absurda toda comparación. Por el contrario, podrían mostrar aspectos de una misma realidad que se reforzarían mutuamente por la menudo disimulada similitud del contenido. $O$ incluso adoptar frente a éste actitudes notablemente semejantes. Esto es, por otra parte, más comprensible si se tiene en cuenta que los medios de comunicación eran más limitados en épocas pasadas, como en la Inglaterra de los siglos XVI y XVII a que vamos a referirnos, en los que la representación dramática cobraba relevancia mediática, como había sucedido en Atenas o en la antigua Roma.

Shakesperare y Hobbes no son estrictamente coetáneos, aunque sí contemporáneos. El gran dramaturgo isabelino y el fundador de la filosofía política moderna vivieron cuando ya el Renacimiento había dejado su impronta en el pensamiento de Occidente, marcando la superación del mundo medieval. Sin excluir a otros importantes pensadores y creadores de la época, ambos representan la modernidad en algunos de sus aspectos más destacados.

\footnotetext{
"Conferencia pronunciada en las Jornadas sobre "Hobbes en su entorno", Universidad Torcuato Di Tella, Buenos Aires, 11 y 12 de Agosto de 1999.
} 
No basta con decir que ambos son en buena medida escépticos, algo que ya se observaba y sin duda de manera más explícita en filósofos como Montaigne o Francisco Sánchez. Los dramas de Shakespeare y las obras filosóficopolíticas de Hobbes manifiestan ese escepticismo muy particularmente en cuestiones como la concepción de la naturaleza humana, sobre la que volveremos un poco más adelante.

¿Pero qué decir acerca del lenguaje mismo que emplean? Sus figuras retóricas no implican que deseen hacer dudar a sus respectivos auditorios de ciertas verdades sino que los alertan sobre las posibilidades de engaño que el lenguaje encierra. La indecisión es otro factor negativo del que intentarán liberarlos en la medida de lo posible mediante una depuración del discurso.

Duda e indecisión abundan en el drama shakespeareano: hay una búsqueda de un terreno más firme, que un escéptico jamás abandona, pero los personajes dramáticos pocas veces parecen sentirse dueños de su destino, lo que también se observa en el hombre natural de Hobbes, dominado por pasiones negativas. En Macbeth, por ejemplo, tres brujas profetizan a Macbeth y a Banquo un destino cuyos signos deben ser descifrados, ya que emplean un lenguaje ambiguo.

Shakespeare, según Saracino, considera que debe haber estabilidad en los signos, pues en caso contrario se compromete la estabilidad de la República, algo de lo que Macbeth, por ejemplo, se da cuenta demasiado tarde. En esta obra, las brujas se burlan de la precisión del lenguaje. Da lo mismo decir que la batalla ha sido ganada que perdida, que el menos feliz es más feliz, que el rey no es rey, que lo mismo es bien que mal. Con referencia a las brujas, dice Saracino: "Su discurso ambiguo tiene por finalidad subvertir el orden jerárquico, puesto que ellas, no afectadas por él, saben que es una sociedad basada en el autoengaño y la opresión" '. Los elementos desestabilizadores son las metáforas, los riddles (acertijos), los puns, que por cierto no están ausentes en los dramas de Shakespeare ${ }^{2}$.

Pero no siempre pone las metáforas en boca de brujas u otros seres maléficos. Por ejemplo, en Hamlet, un drama de indudable trasfondo cristiano, el personaje central cita las cualidades atribuidas a distintos dioses paganos cuando quiere presentar a su padre muerto como poseedor de todas las virtudes: lo compara con Júpiter, Marte y Mercurio, en un discurso explícitamente metafórico.

\footnotetext{
1 Saracino, M., "Hobbes, Shakespeare and the Temptation to Scepticism", Hobbes Studies, Vol.IX, 1966

${ }^{2}$ Cf. op. cit.
} 
En este caso podemos decir que el lenguaje, más allá de su intención laudatoria, cumple una función poética.

Otras veces son los locos los que emplean metáforas, como en King Lear, poniendo de manifiesto que la mente del insano se ha escindido y el lenguaje ha perdido su función racional, conservando sólo la de expresar pasiones y sueños; lo real se diluye en la fantasía. Sin embargo, también es válida la observación contraria: sólo en la locura, quien no se conocía a sí mismo ni a los hombres en general alcanza en algún momento ese conocimiento. King Lear, que se cree mendigo en medio de una tormenta, al llegar a una choza quiere que quienes lo rodean se pongan a salvo antes que él. Toma conciencia de que ellos también padecen y sufren: "Oh, qué poco me he ocupado de esto...Exponéos a sentir lo que sienten los miserables, para que así, al arrojarles lo superfluo, mostréis la mayor justicia de los cielos!"3.

La preocupación por la justicia social que se manifiesta en este pasaje de Shakespeare, resulta notable en tanto históricamente aún no ha llegado la época en que los soberanos se interesaran por el bienestar de los ciudadanos en particular, sino simplemente, tal como aparece en Hobbes, por la estabilidad de un régimen político en que la paz garantice a todos no sólo una mayor seguridad frente a la temida amenaza de la muerte violenta, sino un grado de posibilidad de desarrollo de ciertas actividades. La gran preocupación es la República y su progreso como tal, a través de una buena organización de las instituciones y el cultivo de la ciencia, la industria, las artes, es decir, todo lo que contribuya a su brillo, no al de los individuos. En este aspecto parece prolongarse la visión medieval, en que los artistas y artesanos eran anónimos contribuyentes a una grandeza supra-individual, sólo que en este caso no trascendente sino inmanente a la sociedad política.

En el capítulo XIII del Leviatán, Hobbes alude a los beneficios que aportará a los hombres el establecimiento de la República, exponiendo las carencias de que padecen en el estado de naturaleza. "En tal condición no hay lugar para la industria; porque el fruto de la misma es inseguro. Y, por consiguiente, tampoco cultivo de la tierra; ni navegación; ni uso de los bienes que pueden ser importados por mar; ni construcción confortable; ni instrumentos para mover y remover los objetos que necesitan mucha fuerza; ni conocimiento de la faz de la tierra; ni cómputo del tiempo; ni artes; ni letras; ni sociedad; sino, lo que es peor que todo, miedo continuo, y peligro de muerte violenta; y para el hombre, una vida solitaria, pobre, desgraciada, brutal y corta".

\footnotetext{
${ }^{3}$ The Complete Works of William Shakespeare, Londres, Collins, King Lear, Scene IV, p.1046
} 
Indudablemente, Hobbes tiene en cuenta el progreso que puede alcanzarse en una república organizada, de cuyos primeras manifestaciones tiene conciencia por él estado de la sociedad en que vivía antes de que se desatara la guerra civil, pero ni en éste ni en ningún otro pasaje aparece referencia alguna a la distribución y el acceso a esos bienes que tendrán los distintos ciudadanos en una república.

Volviendo a las figuras retóricas en el texto de Shakespeare, antes de enloquecer o aparentar locura, Hamlet emplea metáforas en el famoso monólogo que se inicia con la frase "ser o no ser": allí la fortuna arroja flechas y los infortunios son como un mar embravecido, mientras que el tiempo agita su látigo. Más adelante, pese a que Polonio parece estar convencido de la locura del príncipe, por momentos duda de ello debido precisamente a algunas metáforas en su discurso que le parecen encerrar un sentido profundo. Para abreviar, citamos sólo una. Dirigiéndose a Polonio, dice Hamlet: “...porque vos mismo, señor, seríais viejo como yo si, como un cangrejo, pudierais caminar hacia atrás"

Hobbes, por su parte, es a veces ambiguo respecto del valor de las metáforas, pero termina condenándolas en el discurso político. Refiriéndose a los usos del lenguaje, dice en un pasaje del Leviatán que a veces lo empleamos para "agradarnos a nosotros mismos y a otros, jugando con nuestras palabras por placer u ornamento, inocentemente" . Parecería querer indicar que las metáforas no son nocivas en sí mismas, en tanto sólo las usemos para complacernos a nosotros mismos o a otros, aunque obviamente, en este último caso, no para comunicar a éstos nuestras ideas, lo que tendría como consecuencia confundirlos. Sin embargo, advertimos que no parece negar legitimidad a la poesía ni, en general, a los usos puramente literarios del lenguaje.

En materia política, por el contrario, Hobbes se manifiesta enemigo de la retórica y de todas sus figuras. Así, en el Capítulo VIII del Leviatán, dice el filósofo que "en la demostración, en el consejo y en toda búsqueda rigurosa de la verdad...las metáforas están ...totalmente excluidas, pues viendo que profesan abiertamente el engaño, admitirlas en el consejo o en el razonamiento sería necedad manifiesta".

Las metáforas sólo se transforman en un "abuso del lenguaje" (la expresión es de Hobbes), cuando no sólo empleamos las palabras en un sentido distinto de aquél que fuera aceptado por convención en una comunidad de hablantes

\footnotetext{
${ }^{4}$ de.cit., Hamlet, Act II, Scene II, p.1140

${ }^{5}$ Hobbes, T., English Works, Tomo III, I, 20
} 
sino que nuestra intención no es deleitarlo sino engañarlo. Sin embargo, se ha observado que "él mismo las emplea [las metáforas] como instrumento eficaz en su propia teoría política. Así, por ejemplo, en el Capítulo XII del Leviatán recurre al mito de Prometeo para ilustrar la condición del hombre que intenta mitigar su temor a la muerte con la esperanza de una vida futura"6.

Dice Hobbes: "Porque así como Prometeo que, interpretado, es el hombre prudente, fue atado a la colina del Cáucaso, un lugar con una amplia perspectiva donde un águila que se alimentaba de su hígado devoraba durante el día tanto como era restaurado durante la noche; así al hombre que mira demasiado lejos hacia adelante con la preocupación del tiempo futuro, le roe durante todo el día el corazón el temor a la muerte, a la pobreza o a otra calamidad y no tiene alivio ni reposo en su ansiedad, excepto en el sueño"7. Es obvio que aquí la metáfora no busca deleitar, pero tampoco engañar, sino que es utilizada deliberadamente por Hobbes para arrancar a los hombres de una preocupación excesiva por el futuro, que considera vana y que les resta energías para ocuparse del presente.

También emplea las dos famosas metáforas del Leviatán y el Beemoth bíblicos - títulos de dos de sus obras - para representar la República. El primero es un monstruo marino, el segundo terrestre, lo que induce a Carl Schmitt a referirse a "la pugna elemental entre la tierra y el mar que fundó el moderno orden político de Europa"8. En muchos casos, Hobbes habla más bien de símiles, otra figura de retórica emparentada con la metáfora, en que la semejanza es claramente explícita, pero es frecuente que se refiera conjuntamente a "símiles o metáforas" Como sostiene Martinich, "en el discurso no -técnico el uso de metáforas es aceptable, y su uso adecuado es signo de una 'buena fantasía', que es una facilidad para identificar similitudes entre las cosas"9. En cambio, en el discurso político, estas figuras de retórica son condenables, por las razones a que nos hemos referido.

En el caso de Hobbes nos resulta mucho más comprensible esta actitud hacia el discurso que en el de Shakespeare, por ser este último un autor dramático que debe emplear los recursos necesarios para atraer a su público. Sin embargo, él también se cuida de que el auditorio no se engañe y por ello pone los símiles o metáforas, tan propios del lenguaje dramático, o bien en boca de los que han perdido la razón, o de aquéllos que buscan perturbar el orden establecido.

\footnotetext{
${ }^{6}$ Costa, M., La filosofía británica en los siglos XVII y XVIII, Buenos Aires, Fundec, 1995, p.233

${ }^{7}$ EW,III,XII,I,95

${ }^{8}$ Smith, K., Hamlet o Hecuba, la irrupción del tiempo en el drama, colección Hestia-Dike, Pretextos, , Universidad de Murcia, España, 1993

${ }^{9}$ Martinich, A.P.,A Hobbes Dictionary, Oxford, Blackwell, 1995, p.205
} 
Así se manifiesta en los dramas de Shakespeare la realidad histórica, a través de personajes sólo a medias ficticios y en situaciones que evocan con frecuencia las que atraviesa su propio país.

En esto puede compararse su estrategia con la de Hobbes, cuyas teorías políticas se aplican muy especialmente a las circunstancias de su época, aunque, universalizadas, pueden tener una aplicación mucho más amplia a los avatares de las repúblicas y sus gobiernos en general.

Apartándonos ahora del lenguaje, un terreno en que Shakespeare y Hobbes son susceptibles de comparación, sea por semejanza o por contraste, quiero referirme ahora a un tema muy importante debatido en la época, que es abordado por ambos autores: el de la naturaleza humana, un tema antropológico, que va más allá de lo puramente psicológico, y que funda una tradición metafísica centrada en el hombre.

Ambos pensadores viven en un momento en que se producía el derrumbe del seguro y ordenado mundo medieval. En éste, el hombre tenía un lugar definido en el universo, en la naturaleza y en el Estado, en función de sus relaciones con Dios, el arquitecto y ordenador universal. Se puede decir que la concepción de hombre era optimista, en tanto, junto con el planeta Tierra, ocupaba un lugar central: para él parecía haberse creado todo lo demás, lo que significaba derechos y obligaciones bien definidos. No obstante, el optimismo no era total, puesto que el hombre debía esforzarse por recuperar parte de esa dignidad, perdida por el pecado original. Era a la vez señor del mundo y un ser caído en él. Con todo, las circunstancias le daban seguridad al hombre: la providencia de Dios, la posibilidad de redención y una promesa de cumplimiento futuro a la que podía aspirar por la fe, avalada por la razón. Si algo faltaba, Dios proveería.

En el siglo XVI, en cambio, se cuestiona la base del acuerdo común acerca del hombre y su lugar en el mundo. En palabras de Theodor Spencer, Copérnico había cuestionado el orden cosmológico, Montaigne el orden natural y Maquiavelo el orden político ${ }^{10}$. Ya la Tierra ha empezado a girar, lo que sin duda producía un malestar casi físico después del seguro apoyo que había parecido brindar.

Montaigne ataca la arrogancia y vanidad del hombre. En Shakespeare este ataque es particularmente duro en Timón de Atenas, un personaje que luego

\footnotetext{
${ }^{10}$ Th.Spencer, Shakespeare and the Nature of .Man, second edition, New York, Collier Books,1966, p.29
} 
de experimentar la hipocresía y superficialidad humanas en su forma más cruda, se va a vivir entre las fieras, a quienes considera mejores que a sus congéneres. Observa que los animales no se hacen la guerra entre sí, lo que prefigura la visión hobbesiana de la "guerra de todos contra todos" aplicada a los hombres en el estado natural. En Timón de Atenas, así como en el Rey Lear y en otras tragedias shakespeareanas, se manifiesta el pesimismo antropológico que caracteriza la filosofía renacentista y que se proyecta en el siglo XVII.

Pero sin duda, Timón de Atenas es la obra más pesimista y "hobbesiana" de Shakespeare. En ella no hay cabida para la bondad o el amor, aun en sus formas más primitivas, y la censura abarca a todos los hombres. Si lo comparamos con Hamlet, por ejemplo, éste concentra el mal en la persona de su madre: no sólo descubre en ella la lujuria y el desenfreno, sino incluso la falta de amor por quien fuera más digno de él, e incluso proyecta en ella la sospecha, justificada o no según los críticos, de que ha participado en un acto criminal de la peor especie. Esto hace de Hamlet un escéptico y, lo que acentúa su carácter trágico es que es el único que se levanta contra el crimen. Horacio es sólo su sombra, quien heredará la tarea de relatar los hechos, aunque sólo podrá hacerlo en general a través de la propia versión hamletiana de los mismos. Pero Hamlet se yergue solo frente al mal y eso hace de él una figura única.

En el Rey Lear se manifiesta una dualidad de naturalezas: una buena, representada por el rey, su hija Cordelia y otras figuras cuyas desventuras parecen reforzar por su similitud las de los personajes centrales, al atravesar circunstancias parecidas; y una naturaleza mala, encarnada por las otras dos hijas de Lear y sus réplicas, como en el caso anterior.

Podríamos continuar la lista de ejemplos de los buenos y los malos en las tragedias de Shakespeare, pero el pesimismo antropológico tiene su mejor manifestación en la mencionada Timón de Atenas, en que la humanidad aparece en sus aspectos más negativos y perversos. En un primer momento, Timón se presenta como un personaje adinerado y generoso, o más bien dispendioso, que derrocha su fortuna dando grandes fiestas y haciendo regalos fastuosos a los que considera sus amigos.

Al comienzo de la obra, ha llegado al punto álgido de su extravagante dadivosidad, rodeado de artistas, nobles y senadores. Timón es presentado como un ser humano noble y generoso, pero los demás no lo aprecian por ello sino por todo lo que obtienen de él. Esto es claro desde un primer momento, y se encarga de ponerlo en evidencia un filósofo cínico -Apemantus - quien introduce la única nota amarga en este principio de la obra. 
Pero Timón pierde toda su fortuna a fuerza de derrocharla y aun llega a endeudarse. Entonces, ninguno de los que habían sido beneficiados por su generosidad acude en su ayuda. Se da cuenta de la hipocresía de todos sus fingidos amigos y se convierte en un misántropo. Se vuelve contra la naturaleza humana, abandona Atenas con una maldición y se va a vivir entre las bestias salvajes.

Esta pintura que nos da Shakespeare de Timón de Atenas en esta segunda parte de su obra, es un ejemplo - curiosamente anticipado - de lo que será para Hobbes el estado de naturaleza. Este funda su concepción de la naturaleza humana en sus principios metafísicos básicos de que todo lo que existe es material y de que el fenómeno universal es el movimiento. Así, de la misma manera en que todos los cuerpos físicos tienden a mantener dicho movimiento transmitiendo ese impulso a otros cuerpos y recibiendo de ellos el que necesitan para continuar cambiando continuamente de lugar, produciendo así un movimiento circular universal de todas las cosas creadas, los hombres, que no constituyen una excepción a la teoría mecanicista, son llevados por sus impulsos y pasiones a luchar contra sus semejantes.

La principal característica de ese cuerpo en que consiste el hombre es un movimiento al que llamamos su instinto de auto-preservación o conservación o, en otras palabras, su impulso vital, que comparte con todos los seres vivos, pero que adquiere en él ciertas características particulares en función de las pasiones que le son propias. Debido a la consigna general de su sistema, que podemos considerar como un materialismo mecanicista en el que se ha tratado de eliminar las causas finales y sobre todo la referencia a un fin último o supremo, la naturaleza humana es considerada por Hobbes como extremadamente agresiva, egoísta y codiciosa.

Hasta el momento en que se constituye la República, el hombre vive en lo que Hobbes llama "estado de naturaleza", que puede ser inferido a partir de las pasiones de los hombres. Es una descripción, por cierto hipotética, a pesar de que Hobbes intenta en ocasiones darle un carácter histórico, del estado primitivo de la humanidad, es decir, de cómo vivirían los hombres si no estuvieran sometidos a un gobierno.

En ese estado los hombres luchan entre sí: es la "guerra de todos contra todos". Las pasiones que los conducen a esa lucha son la ambición de poder, que los lleva a tratar de arrebatarle al otro aquello que tiene, la desconfianza, que los lleva a agredir primero por temor a ser agredidos, y el afán de gloria - la vanagloria - que los conduce a luchar por meras cuestiones de prestigio o preferencia. 
Lo que pone fin a esta terrible situación es la razón: cuando esta surge en un determinado momento de maduración ontogenética, los hombres comprenden que no podrán sobrevivir - y por cierto le temen a la muerte - a menos que depongan sus pasiones y lleguen a un acuerdo que les permita vivir en paz. Este acuerdo es el pacto, por el que renuncian a su derecho a todas las cosas y lo ceden a un soberano, que no pacta, y al que se comprometen a obedecer por su seguridad y la preservación de su vida.

Este estado de naturaleza aparece precisamente en Timón de Atenas, drama que fue escrito con bastante anticipación al Leviatán de Hobbes. ¿Qué son para Timón los hombres sino fieras que buscan destruirse unos a otros? Si no viviesen en una sociedad política - Atenas, en la ficción shakespeareana - los hombres, sin bienestar económico ni seguridad garantida por instituciones civiles - se destruirían unos a otros, incapaces de sentimientos nobles y solidarios naturales. En esta obra aparece sin duda la ambición de poder, representada por lo bienes materiales cuya adquisición todos persiguen constantemente, acompañada de la vanagloria, ya que no persiguen ideales superiores sino meros halagos. El propio Timón puede ser interpretado, en este sentido, como alguien muy sensible a las adulaciones, aunque Shakespeare parece inclinarse por darnos de él una imagen generosa y ajena al cálculo que predominaba en su entorno.

Apemantus, el filósofo cínico (un Hobbes realista), quiere mostrarle los aspectos negativos de la sociedad de los hombres, pero no lo logra porque Timón respira una atmósfera engañosamente placentera y amable. Todos son sus amigos; no dejarán de ayudarlo cuando los necesite, como él los ha ayudado a ellos. Pero de pronto esta visión se derrumba. La situación cambia para Timón y le hace percibir la auténtica realidad: los hombres son egoístas y malvados; cada uno busca su propio bien, entendido materialmente.

Timón se aparta de Atenas y se va a vivir entre salvajes.

La selva de Timón es, pues, el estado de naturaleza del hombre. Estos son las fieras que se devoran entre sí, como caníbales, al quedar despojados del velo de hipocresía que los hacía aparecer como nobles ciudadanos. Nadie logrará arrancar al misántropo de su estado salvaje y la muerte será, no algo temible como en Hobbes, sino el único camino para escapar de los peores seres de la Creación: sus congéneres.

Si en las comedias Shakespeare nos ha dado una pintura más benévola de los hombres, llegando a mostrarnos el triunfo del bien, como en La Tempestad, en las tragedias el mal está siempre presente. La muerte llega como un lógi- 
co corolario. Los nobles o los propios súbditos asesinan a su reyes y el Estado se derrumba, debiendo el monarca legítimo ser reemplazado por otro que aparece como un salvador y es aceptado por el pueblo como alguien que ha de protegerlos de si mismos y de sus enemigos exteriores. Es una anticipación de la concepción hobbesiana de la República: al soberano no lo manda Dios, no reina por derecho divino, sino que los hombres lo eligen en circunstancias caóticas para que introduzca el orden y garantice la paz. Fortinbras en Hamlet o Kent y Edgar en King Lear o Alcibíades en Timon of Athens representan esas figuras .

Por eso la República está al final, no al comienzo de las obras de Shakespeare, como en Hobbes el estado civil es precedido por el estado de naturaleza.

Me parece un esfuerzo condenado al fracaso descontextualizar a Shakespeare de su entorno histórico-político, como lo sería intentar descontextualizar por completo a Hobbes. Guerras, odios y temores ponen a los hombres en situaciones que los conducen a aceptar una salida política a estados de cosas creados por las pasiones naturales. El bien, que no está ausente por completo, es demasiado débil contra el mal que domina la naturaleza humana. Así, Shakespeare nos presenta en variados escenarios y Hobbes en el paradigmático de la monarquía de los Estuardo, la realidad de los hombres desde una similar perspectiva antropológica.

\section{Resumen}

El objetivo de este artículo es sacar a luz las semejanzas entre un dramaturgo y un filósofo político, respecto de su uso del lenguaje y del fundamento antropológico de sus ideas políticas. Las metáforas se consideran inevitables en un poeta como Shakespere, pero ellas son condenadas por Hobbes como un abuso retórico que el discurso político debe evitar. Se comparan sus enfoques pesimistas de la naturaleza humana y finalmente se pone acento en el contexto histórico, que marca el comienzo de la época moderna.

\section{Abstract}

The aim of this paper is to bring out the similarities between a playwright and a political philosopher, both in their use of language and in the anthropological foundations of their political ideas. Emphasis is laid on metaphors, unavoidable in a poet like Shakespeare, but condemned by Hobbes as a rhetorical abuse that political discourse should avoid. After comparing their pessimistic approaches to 
human nature, stress is laid on the historical context, which marks the beginning of modern times. 